\title{
Design of self-healing biodegradable polymers
}

\author{
Liberata Guadagno $^{1} \cdot$ Marialuigia Raimondo ${ }^{1} \cdot$ Michelina Catauro $^{2} \cdot$ Andrea Sorrentino $^{3} \cdot$ Elisa Calabrese $^{1}$ (i)
}

Received: 4 June 2021 / Accepted: 3 January 2022 / Published online: 24 January 2022

(c) The Author(s) 2022

\begin{abstract}
A biodegradable thermoplastic polymer has been formulated by solubilizing Murexide (M) salts in a commercial biodegradable vinyl alcohol copolymer (HVA). The Murexide has been employed as a self-healing filler with the aim to impart the auto-repair ability to the formulated material. Three different percentages (1,3, and 5 mass\%) of filler have been solubilized in HVA to evaluate the effect of the filler concentration on the thermal and self-healing properties of the resulting polymeric materials. The samples have been thermally characterized by Differential Scanning Calorimetry (DSC) and Thermogravimetric Analyses (TGA), while their self-healing ability has been evaluated through the estimation of the storage modulus recovery, measured by Dynamic Mechanical Analysis (DMA). The results of DSC analysis have highlighted that the increase of the amount of Murexide anticipates the thermal events such as glass transition, crystallization and melting. TGA measurements have evidenced that, although there is a reduction of thermal stability of the materials in the presence of a high concentration of $\mathrm{M}$, the polymer still remains stable up to $270{ }^{\circ} \mathrm{C}$. Healing efficiency higher than $80 \%$, at a temperature beyond $60{ }^{\circ} \mathrm{C}$, has been detected for the samples loaded with 3 and 5 mass\% of Murexide, thus confirming the efficacy of this compound as an auto-repair agent and the relationship between the self-healing efficiency and its amount. For a temperature lower than $70{ }^{\circ} \mathrm{C}$, the healing tests, carried out at different values of tensile deformation frequency, have highlighted a frequency-dependent healing efficiency. This dependence becomes negligible at higher temperatures for which the healing efficiency approaches the value of $100 \%$.
\end{abstract}

Keywords Self-healing nano-composites $\cdot$ Green polymer $\cdot$ Thermal properties

\section{Introduction}

Today, one of the main purposes of the research in the field of materials science is undoubtedly the development of new products with increased durability, concrete advantages in terms of safety, costs, and environmental impact [1]. To this purpose, more and more attention is paid to the study of the so-called "self-healing" materials. The concept of self-healing refers to the ability of the material to re-establish its own intrinsic balance, following damage suffered by an external

Elisa Calabrese

elicalabrese@unisa.it

1 Department of Industrial Engineering, University of Salerno, Via Giovanni Paolo II 132, 84084 Fisciano, Italy

2 Department of Engineering, University of Campania "Luigi Vanvitelli,,", Via Roma 29, 813031 Aversa, Italy

3 Institute of Polymers, Composites and Biomaterials (IPCB), National Research Council of Italy (CNR), P.le E. Fermi, 1, 80055 Portici, NA, Italy cause. From this point of view, it is possible to distinguish between so-called autonomous systems and non-autonomous systems. In the former, the self-healing mechanism is triggered by the damage itself, while in the latter, this potentiality requires external intervention to being activated. A successful autonomous self-healing system is that based on the microencapsulation strategy, which has reached important milestones in the design of Ring-Opening Metathesis Polymerization (ROMP) catalysts to be used in thermosetting resins for structural applications [2-5].

In recent years, research advancement has made it possible to develop new commercial products, especially in the automotive, aerospace, and construction industries. Examples are paints capable of self-eliminating any scratches or surface damage. The conditions that allow the system to work can be very different, based on the nature of the material and the type of chemical bond involved [6]. Examples of non-covalent bonds are the hydrogen bond, the metal-ligand coordination bond, ionic, and $\pi-\pi$ stacking interactions. The relatively weak nature of these interactions means that their 
delicate balance is particularly sensitive to the environment in which they are found [6]. Due to its characteristics of directionality and versatility, the hydrogen bond certainly represents one of the most exploited non-covalent interactions in the context of supramolecular systems. For thermoplastic polymeric systems, this kind of interaction can be combined with other characteristics, such as a significant number of repetitive units, which allows not only to obtain a good polymerization degree, but also (if the chemical structure of the polymer is suitable) the establishments of multiple and repeated interactions, able to create relevant synergistic effects. This can be achieved either by using multiple $\mathrm{H}$ bonds or by combining additional forces to the hydrogen bond, such as those based on $\pi-\pi$ stacking interactions. The strategy based on the use of multiple bonds is at the heart of the thermal control system developed by the group of Prof. Bert Meijer, a polysilane with two ureidopyrimidine end groups (UPy) capable of forming a quadruple self-complementary $\mathrm{H}$ bond [7].

This type of unit has been widely used, both for its synthetic accessibility and for its high association constant, resulting in numerous publications and patents. A compound bearing the UPy unit was, for example, exploited for the production of a hydrogel capable of expressing its self-healing potentiality already at room temperature, following the simple contact between the cut parts [8].

A problem encountered in the design of self-healing materials based on reversible interactions is the lack of good mechanical properties. In order to overcome this no-trivial issue, several approach strategies have been proposed and, among these, an important role is played by those involving the use of polymers combined with nanofillers, which allow to producing new self-responsive multifunctional materials having high mechanical performance [9-21]. A similar auto-repair approach can be integrated in commercial biodegradable polymers, having excellent gas barrier properties [22-25], which can be modified to favor the activation of self-healing mechanisms. In order to confer improved mechanical properties and electrical conductivity to biomaterials, carbon nanotubes have been added to the polymer matrix. A critical point in the use of such nanofillers is their dispersion and adhesion with the polymer matrix [26]. To overcome this critical issue, different approaches have been employed, such as those involving the use of ionic liquids (ILs) [27-29] or those based on the use of masterbatches, composed of Carbon Nanotubes (CNT) mixed with a compatible polymer [22-26, 30, 31], which also allow solving problems related to the CNT-powders handling, as the danger inhalation during the material preparation.

In a previous work, the authors applied this last strategy to produce a completely biodegradable polymer blend, constituted by a CNT modified carboxyl methyl cellulose (CMC) masterbatch and a commercial biodegradable highly amorphous vinyl alcohol polymer (HVA) [22-24, 32, 33]. This green nanocomposite was filled with Murexide, a molecule whose structure allows confer self-healing properties to the material due to its capacity to interact with the hydroxyl and carbonyl groups of the hosting matrix through H-bonds. The satisfactory results obtained with the HVA polymer loaded only with the self-healing filler, without masterbatch, led the authors to evaluate how the variation of the filler amount can influence the self-healing efficiency of the composite, adding a new advance in the study of functional biodegradable materials, potentially suitable for different industrial applications, such as coating or food and biomedical packaging [23, 24, 34-37].

\section{Experimental}

\section{Formulation of the materials}

The thermoplastic matrix employed for the preparation of the samples is a biodegradable vinyl alcohol copolymer, patented and commercialized with the trade name Nichigo G-Polymer (grade OKS 8049). It was provided from Nippon Gohsei Synthetic Chemical Industry, Europe GmbH, Düsseldorf, and here is named with the acronym HVA.

The compound used as a self-healing agent is the Murexide, a dark purple powder purchased by Merck (Merck KGaA Darmstadt, Germany) and indicated with the acronym $M$.

Figure 1 shows the physical aspect and the chemical structures of the two employed components (HVA polymer and $\mathrm{M}$ compound).

For the preparation of the samples, HVA pellets were solubilized in deionized water, heating the solution at a (a)
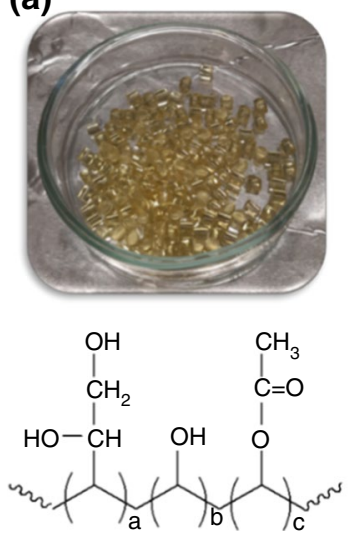

(b)
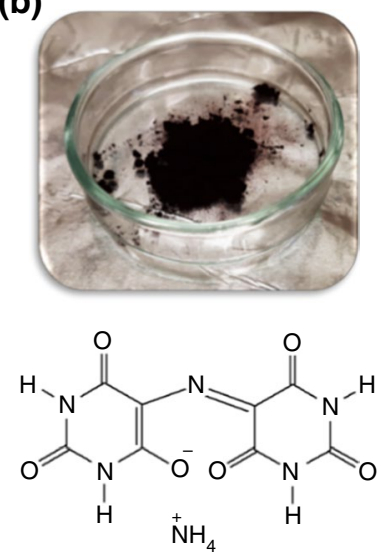

Fig. 1 a Visualization of HVA polymer in the form of pellets and chemical formula of HVA polymer; $\mathbf{b}$ Visualization of $\mathrm{M}$ compound in the form of powders and chemical formula of $\mathrm{M}$ compound 
temperature of $80{ }^{\circ} \mathrm{C}$ for two hours and under magnetic stirring. Subsequently, the Murexide salt was added; the resulting mixture was kept under magnetic stirring until complete solubilization of the M powders. A ratio polymer/ water of $5 \mathrm{~g} / 50 \mathrm{~mL}$ was chosen. Finally, the liquid blend was poured in a petri dish (see Fig. 2a) and the films, with a thickness of 500-600 $\mu \mathrm{m}$, were obtained after a week, by casting evaporation method. Table 1 shows the composition of the four formulated samples. Of these, HVA is the reference sample and does not contain Murexide (M), while HVA-1 M, HVA-3 $\mathrm{M}$ and, finally, HVA-5 $\mathrm{M}$ contain three different percentages of Murexide (M), namely 1, 3, and 5 mass $\%$, respectively.

Pictures reported in Fig. 2b show the final film of HVA-1 M sample, highlighting its high flexibility.

\section{Characterization of the materials}

The samples were thermally characterized by DSC and TGA analyses.

DSC analysis was performed under nitrogen atmosphere by employing an amount of sample of about $5-7 \mathrm{mg}$. A Mettler DSC 822/400 instrument (Mettler-Toledo Columbus, $\mathrm{OH}$, USA) was used. The experimental tests were carried out performing a three scanning runs method, with a rate of $10{ }^{\circ} \mathrm{C} \mathrm{min}{ }^{-1}$. The DSC cycle was composed of a first heating run from -30 to $220^{\circ} \mathrm{C}$, a cooling run from 220 to $-30^{\circ} \mathrm{C}$ and a second heating run from -30 to $220^{\circ} \mathrm{C}$.

DSC measurements were carried out to estimate the crystallization temperature $T_{\mathrm{c}}$ and the melting temperature $T_{\mathrm{m}}$, evaluated from the maximum of the exothermic peak of the cooling run and from the maximum of the endothermic peak of the second heating run, respectively. Furthermore, the glass transition temperature $T_{\mathrm{g}}$ was evaluated as the middle point of the second order transition of the second heating run, and the relative crystallinity $X_{\mathrm{c}}$, calculated by using the Eq. 1 [38], where $\Delta H_{\mathrm{m}}^{0}$ is the melting heat for $100 \%$ crystalline PVOH (138.6 $\mathrm{Jg}^{-1}$ ) [39] and $\Delta H_{\mathrm{m}}^{0}$ is the melting heat of the analyzed sample, determined by the evaluation of the total area under the endothermic peak of the third run.
Table 1 Composition of the formulated samples

\begin{tabular}{ll}
\hline Samples & $\begin{array}{l}\text { Percentage of } \\
\text { Murexide/\% }\end{array}$ \\
\hline HVA & 0 \\
HVA-1 M & 1 \\
HVA-3 M & 3 \\
HVA-5 M & 5 \\
\hline
\end{tabular}

$X_{\mathrm{c}}=\frac{\Delta H_{\mathrm{m}}}{\Delta H_{\mathrm{m}}^{0}} \times 100$

The crystallization heat $\Delta H_{\mathrm{c}}$ was determined from the evaluation of the total area under the exothermic peak of the second scanning run.

DSC cell was purged with nitrogen and chilled with liquid nitrogen for sub-ambient measurements.

TGA analysis was performed in air flow by using a Mettler TGA/SDTA 851 (Mettler-Toledo Columbus, OH, USA) instrument, heating about $7.0-8.0 \mathrm{mg}$ of the sample from 30 to $900{ }^{\circ} \mathrm{C}$, with a heating rate of $10{ }^{\circ} \mathrm{C} \mathrm{min}-1$.

The healing efficiency of the samples was determined by Dynamic Mechanical Analysis (DMA), carried out on a DMA 2980 TA instrument (New Castle, DE 19,720, USA), in Tensile mode and following a procedure already described in literature [33]. The range of analyzed temperature was from 30 to $110^{\circ} \mathrm{C}$, at the constant scanning rate of $3{ }^{\circ} \mathrm{C} \mathrm{min}{ }^{-1}$ and at the frequency of $1 \mathrm{~Hz}$. For the HVA-1 M and HVA-5 M samples further DMA tests at different values of tensile deformation frequency $(10,32$, and $100 \mathrm{~Hz})$ were performed, in isothermal conditions, at constant values of temperature, corresponding to $32,50,70,90,110$, and $130^{\circ} \mathrm{C}$.

The healing efficiency was calculated as the recovery of storage modulus, according to the Eq. 2

$\frac{E_{\mathrm{SH}}}{E_{\mathrm{V}}} \times 100$

where $E_{\mathrm{SH}}$ is the storage modulus of the healed sample and $E_{\mathrm{V}}$ the storage modulus of the virgin sample. For each
Fig. 2 Pictures showing: a HVA-1 $\mathrm{M}$ (on the left) and HVA-5 $\mathrm{M}$ (on the right) liquid mixtures poured into Petri dish; b HVA-1 M film in dry condition (after water evaporation)

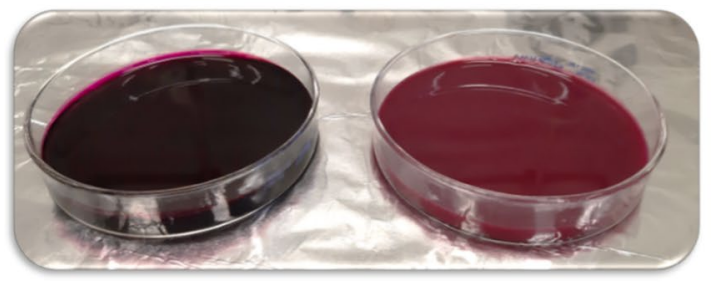

(a)

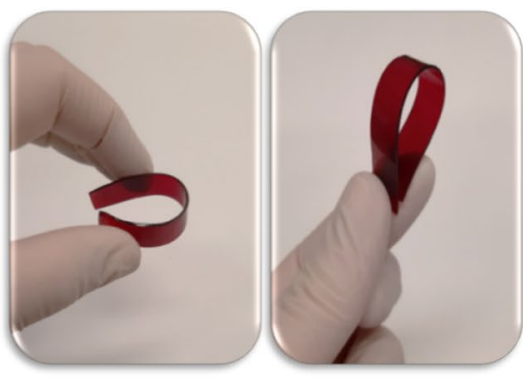

(b) 
sample the test was performed five times, obtaining similar results.

\section{Results and discussion}

\section{Evaluation of thermal properties}

Thermal analysis was performed on the formulated samples with the aim to understand the effect of the variation of the Murexide filler amount on the thermal properties of the HVA co-polymer.

Figure $3 \mathrm{a}$ and $\mathrm{b}$ shows the DSC curves of the analyzed samples. Figure $3 c$ illustrates a histogram reporting the crystallization $\left(T_{\mathrm{c}}\right)$ and the melting $\left(T_{\mathrm{m}}\right)$ temperatures for each sample, while Fig. 3d shows a histogram with the glass transition temperature values $\left(T_{\mathrm{g}}\right)$ detected by DSC analysis. The profiles of DSC curves belong to the cooling scan (from 210 to $-30{ }^{\circ} \mathrm{C}$, see Fig. 3a) and to the second heating scan (from -30 to $210{ }^{\circ} \mathrm{C}$ ). The curves related to
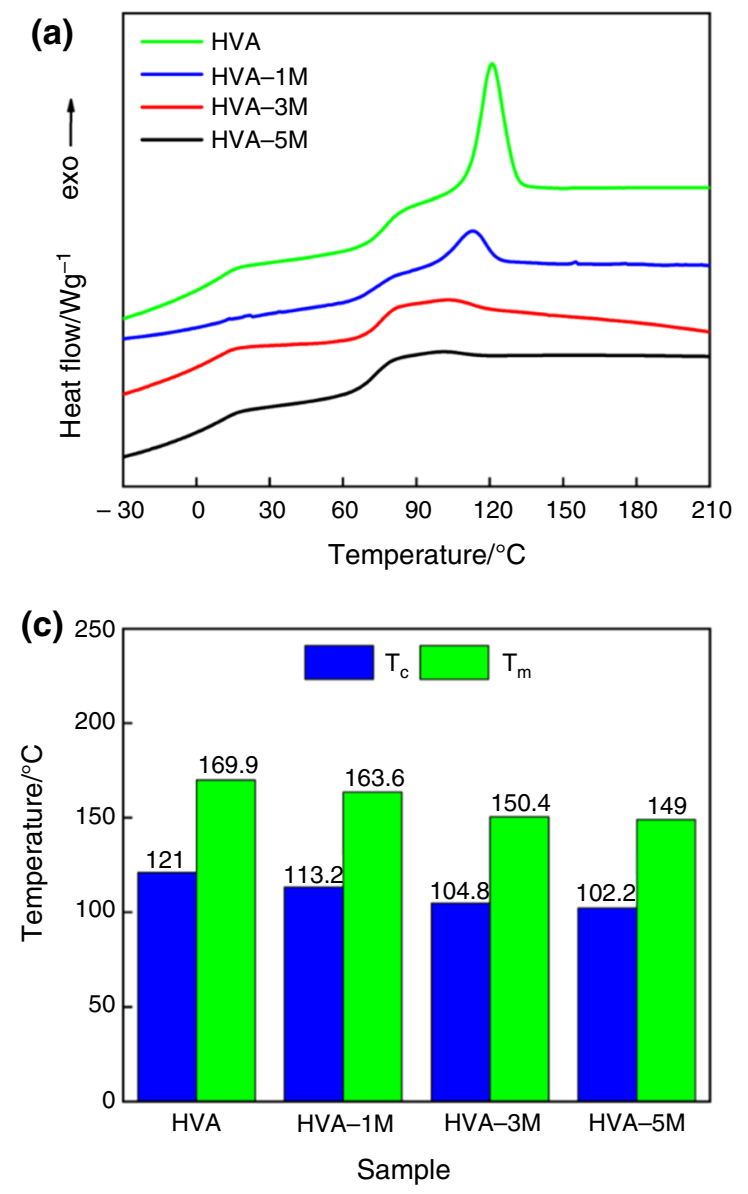

Fig. 3 Results of DSC analysis for the tested composites: a DSC curves of the cooling run (from 210 to $-30{ }^{\circ} \mathrm{C}$ ); b DSC curves of heating run (from -30 to $210^{\circ} \mathrm{C}$ ); $\mathbf{c}$ Histogram representing the val- the first heating run (from -30 to $210{ }^{\circ} \mathrm{C}$ ) are not reported here, because they are not diagnostic of any thermal event associated to the materials [33, 38]. The presence of the $\mathbf{M}$ compound in the HVA polymer determines a slight decrease in both crystallization $\left(T_{\mathrm{c}}\right)$ and melting $\left(T_{\mathrm{m}}\right)$ temperatures of the resulting composites; in fact, $T_{\mathrm{c}}$ and $T_{\mathrm{m}}$ decrease with increasing $\mathrm{M}$ amount (see Fig. 3c). A gradual reduction of $\Delta H_{\mathrm{c}}$ and $\Delta H_{\mathrm{m}}$ values are also observed with the increase of the filler amount, which determines a consequent decrease in the crystallization degree $X_{\mathrm{c}}$ (see Table 2). It is worth noting that the decrease in $\Delta H_{\mathrm{m}}$, with the increase of the

Table 2 DSC data

\begin{tabular}{lclr}
\hline Sample & $\Delta H_{\mathrm{c}} / \mathrm{Jg}^{-1}$ & $\Delta H_{\mathrm{m}} / \mathrm{Jg}^{-1}$ & $X_{\mathrm{c}}$ \\
\hline HVA & 23.2 & 26.8 & 19.3 \\
HVA-1 M & 6.2 & 21.7 & 15.7 \\
HVA-3 M & 1.2 & 22.1 & 15.9 \\
HVA-5 M & 0.3 & 11.5 & 8.3 \\
\hline
\end{tabular}

(b)

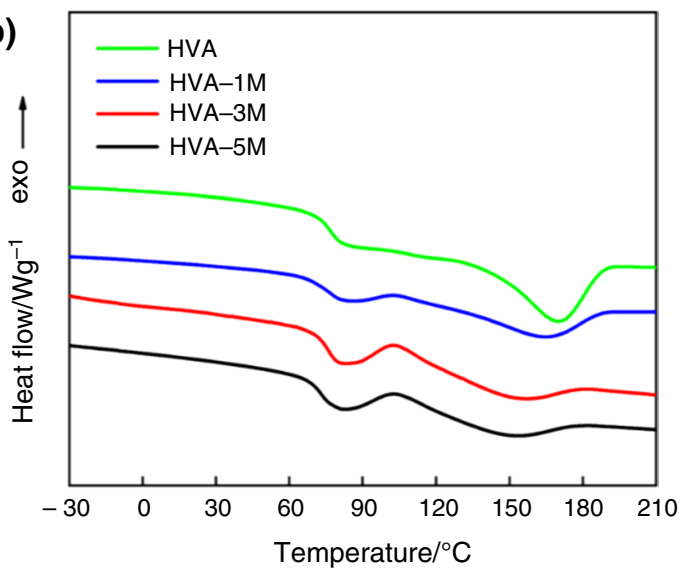

(d)

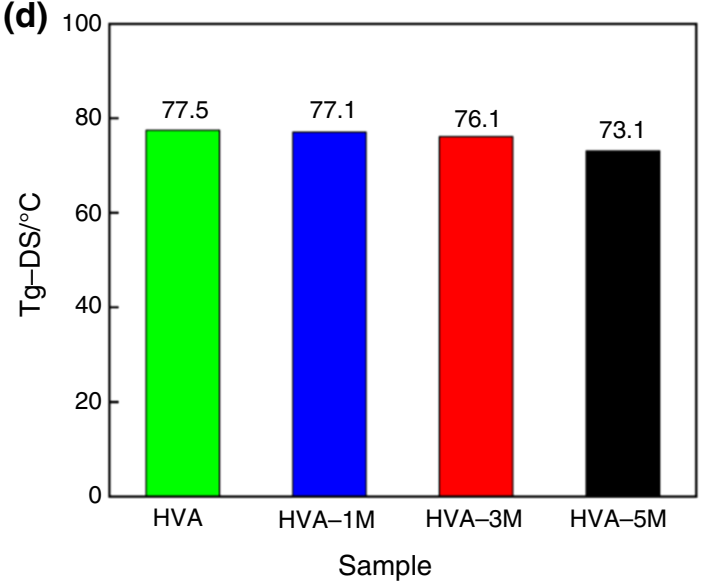

ues of crystallization $\left(T_{\mathrm{c}}\right)$ and melting $\left(T_{\mathrm{m}}\right)$ temperatures; d Histogram representing the glass transition temperature values detected by DSC $\left(T_{\mathrm{g}}\right.$-DSC) 
percentage of Murexide, is less marked than the decrease in the crystallization temperature $\Delta H_{\mathrm{c}}$. This trend can be easily understood by observing the profile of the curves in Fig. 3b, where it is observed that immediately after the glass transition temperature the presence of $\mathrm{M}$ determines an exothermic peak of crystallization. This behavior is not observed for the pure copolymer, which manifests a traditional second-order transition associated with the $T_{\mathrm{g}}$. This highlights that when the polymer chains are endowed with sufficient mobility (at the $T_{\mathrm{g}}$ value or at higher temperatures) the sample continues to crystallize during thermal scanning. Thus, the sample containing Murexide contains a higher amorphous phase fraction than the pure copolymer. Part of this amorphous phase crystallizes during thermal scanning at temperatures above $60-70{ }^{\circ} \mathrm{C}$. In particular, the addition of 1 mass \% of $\mathrm{M}$ determines a decrease of about $8{ }^{\circ} \mathrm{C}$ in the $T_{\mathrm{c}}$ value, (see Fig. $3 \mathrm{a}$ and c). The presence of 5 mass\% of $\mathrm{M}$ causes a higher reduction of the crystallization temperature, with a shift of the exothermic peak from 121.0 to $102.2{ }^{\circ} \mathrm{C}$. A similar behavior is also detectable for the variation of the melting temperature. Hence, together with a higher amount of the amorphous phase in the polymer containing Murexide, it is also observed that the crystallites are smaller in size and with a greater extent of surface defects. Concerning this last aspect, it is well evident in Fig. 3b that an increase of 5 mass \% of $\mathrm{M}$ determines a reduction in the melting temperature from about $170{ }^{\circ} \mathrm{C}$ for the neat HVA, to about $150{ }^{\circ} \mathrm{C}$ for HVA-5 M sample. Furthermore, data in Table 2 show that also the values of $\Delta H_{\mathrm{c}}$ and $\Delta H_{\mathrm{m}}$ diminish with the increment of the Murexide percentage, consequently determining a strong decrease of $X_{\mathrm{c}}$ for the sample HVA-5 M. This effect evidences that the crystallization behavior of HVA co-polymer is highly influenced by $\mathrm{M}$ filler amount, that, if present in high percentage, is able to arrange a bigger number of intermolecular interactions with the HVA polymer, hindering the growth of crystals and making the sample more amorphous. Concerning the $T_{\mathrm{g}}$ values, the histogram in Fig. 3d shows that the presence of 1 mass\% of $\mathrm{M}$ does not influence the glass transition temperature, that remains almost unaltered (about $77^{\circ} \mathrm{C}$ ), while, increasing the percentage of $\mathrm{M}, T_{\mathrm{g}}$ slightly decreases, assuming a value of about $73{ }^{\circ} \mathrm{C}$ for HVA-5 M sample.

These results highlight that, raising the amount of Murexide, an increase of material's flexibility occurs, thanks to an enhancing of the hydrogen bonding interactions established between the HVA matrix and the filler.

Figure $4 \mathrm{a}$ and $\mathrm{b}$ shows the TGA curves and the derivative mass loss curves (indicated also as DTGA curves), respectively, as a function of temperature for each formulated sample. The measurements were taken in air flow and they were carried out on the samples dried in vacuum for $8 \mathrm{~h}$ at $60{ }^{\circ} \mathrm{C}$, in order to eliminate most of the water present in the materials. Table 3 shows the values of the beginning thermal degradation temperature $\mathrm{T}_{\mathrm{d} 5 \%}$, corresponding to a mass loss of 5 mass $\%$, and the temperatures of thermal degradation $\mathrm{T}_{\mathrm{d} 50 \%}$, corresponding to a mass loss of 50 mass\%. The presence of a small peak between 110 and $150^{\circ} \mathrm{C}$, in the DTGA curves of Fig. 4b, evidences that all the materials show a first thermal event, corresponding to a mass loss of about 5

Table 3 TGA data of the dried samples (dried in oven at $60{ }^{\circ} \mathrm{C}$ for $8 \mathrm{~h}$ )

\begin{tabular}{llll}
\hline Sample & $T_{\mathrm{d} 5 \%} /{ }^{\circ} \mathrm{C}$ & $T_{\mathrm{d} 50 \%} /{ }^{\circ} \mathrm{C}$ & $\begin{array}{l}\text { Residue } \\
\text { at } 900{ }^{\circ} \mathrm{C}\end{array}$ \\
\hline HVA & 302.6 & 373.8 & 1.5 \\
HVA-1 M & 297.8 & 365.3 & 2.3 \\
HVA-3 M & 283.8 & 356.5 & 2.6 \\
HVA-5 M & 277.2 & 357.5 & 1.5 \\
\hline
\end{tabular}
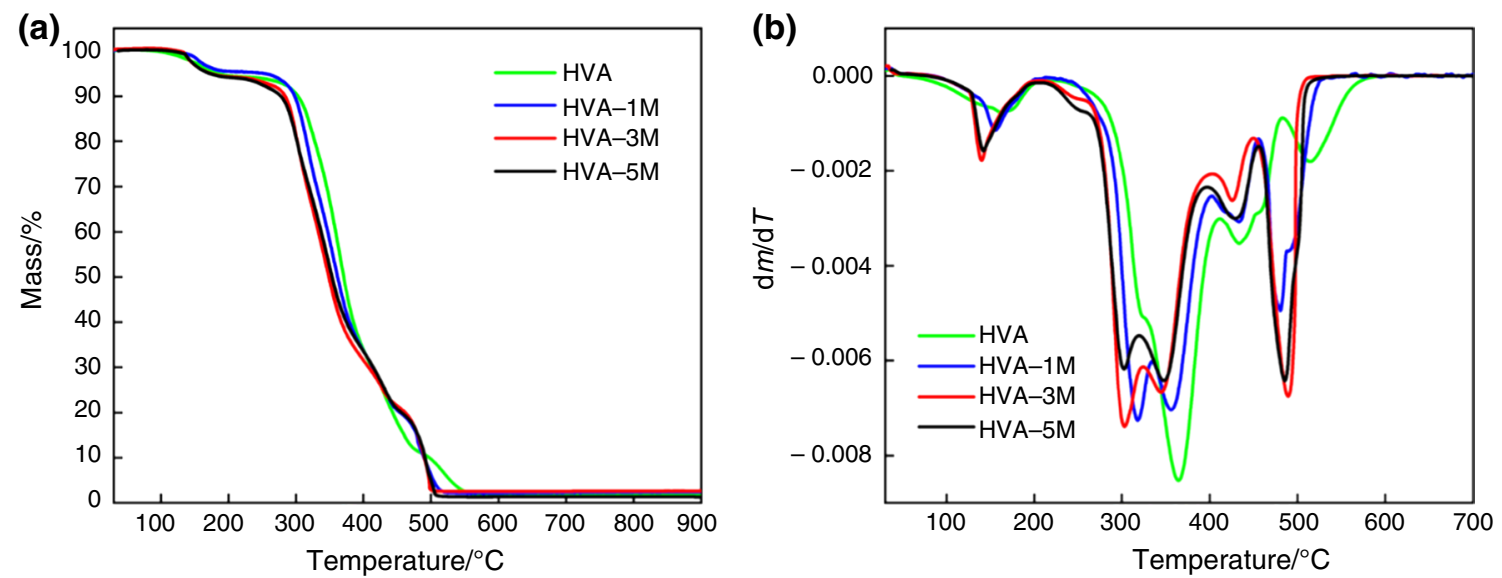

Fig. 4 Results of TGA analysis: a Mass loss curves and $\mathbf{b}$ derivative mass loss curves as a function of temperature for the analyzed dried samples (dried in oven at $60{ }^{\circ} \mathrm{C}$ for $8 \mathrm{~h}$ ) 
mass \% that can be attributed to the removal of residual water (bound water). It is worth noting that the $T_{\mathrm{d} 5 \%}$ and $T_{\mathrm{d} 50 \%}$ values for all the samples were determined considering this last hypothesized event. The profiles of TGA and DTGA curves for the pristine HVA highlight that the main thermal degradation stage is between 350 and $440{ }^{\circ} \mathrm{C}$ (see green curve in Fig. 4b). The addition of Murexide modifies this profile, splitting the main DTGA peak in two peaks located in the temperatures range of $300-435{ }^{\circ} \mathrm{C}$, for the samples containing $\mathrm{M}$ (see blue, red and black curves in Fig. 4b). Furthermore, with the increasing of the $\mathrm{M}$ amount into the HVA matrix, the two peaks are shifted to lower values of temperatures. A similar trend is observable for the second relevant thermal degradation step around $500{ }^{\circ} \mathrm{C}$. These results, combined with the $T_{\mathrm{d} 5 \%}$ and $T_{\mathrm{d} 50 \%}$ values, evidence that the thermal stability of the samples slightly decreases with increasing Murexide percentage.

\section{Evaluation of self-healing efficiency}

The healing efficiency of the samples was evaluated as the recovery of the storage modulus of the healed sample with respect to the virgin sample, according to Eq. 2 reported in the experimental section. The range of temperatures analyzed was between 30 and $110^{\circ} \mathrm{C}$. These values of temperature were chosen to simulate the common life-service conditions of the formulated materials. The graphs in Fig. 5 show the healing efficiency on the right axis and the storage modulus of the virgin sample (continuous curve) and of the healed sample (dashed curve) on the left axis, as a function of the temperature, for each formulated polymeric system. The data evidence that the pristine HVA (see Fig. 5a) shows only a partial recovery of the storage modulus, manifesting around $30{ }^{\circ} \mathrm{C}$ a maximum healing efficiency of $75 \%$, that decreases at the increasing of the temperature, reaching a percentage of about $50 \%$ at $110{ }^{\circ} \mathrm{C}$. HVA copolymer already manifest auto-repair ability, probably due to the presence of hydroxyl and carbonyl functional groups able to establish H-bonding interactions. These interactions are destroyed with the rising of the temperature and the consequent growth of the chain segment mobility. The presence of Murexide strongly enhances the intrinsic self-healing ability. The presence of 1 mass\% of $\mathrm{M}$ (see Fig. 5b) determines a maximum in the healing efficiency curve (almost $80 \%$ ) at about $60^{\circ} \mathrm{C}$. After (a)
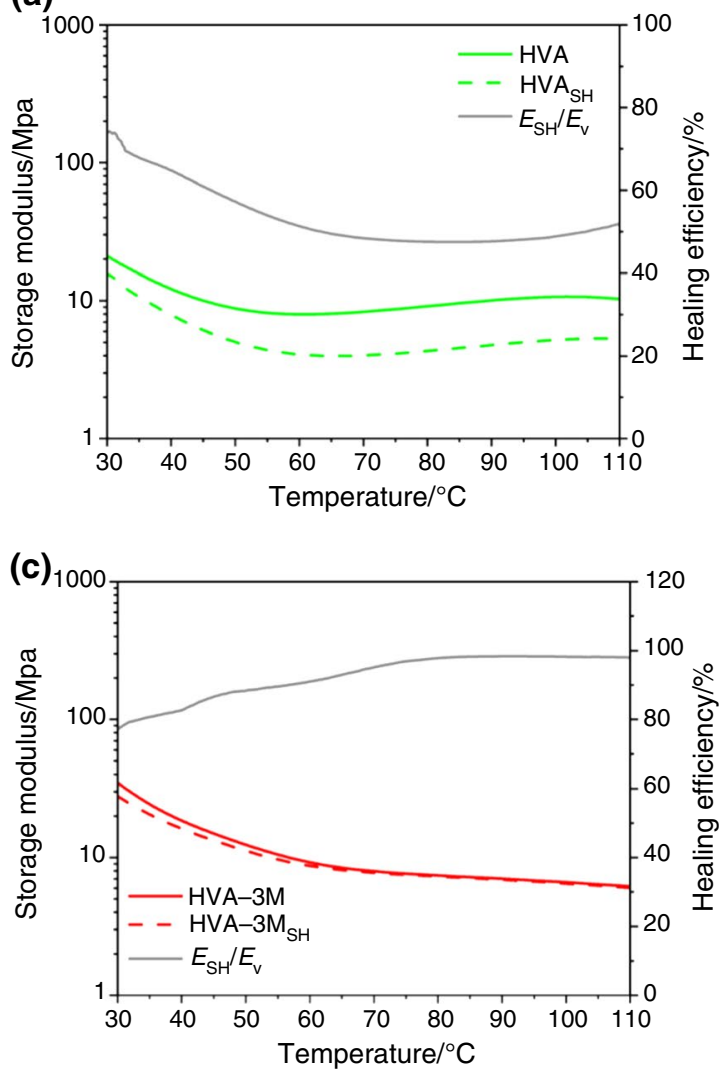

Fig. 5 Graphs representing the Storage Modulus (on the left axis) of the virgin sample (see continuous curve) and of the healed sample (see dashed curve), and the Healing Efficiency (on the right axis) (b)
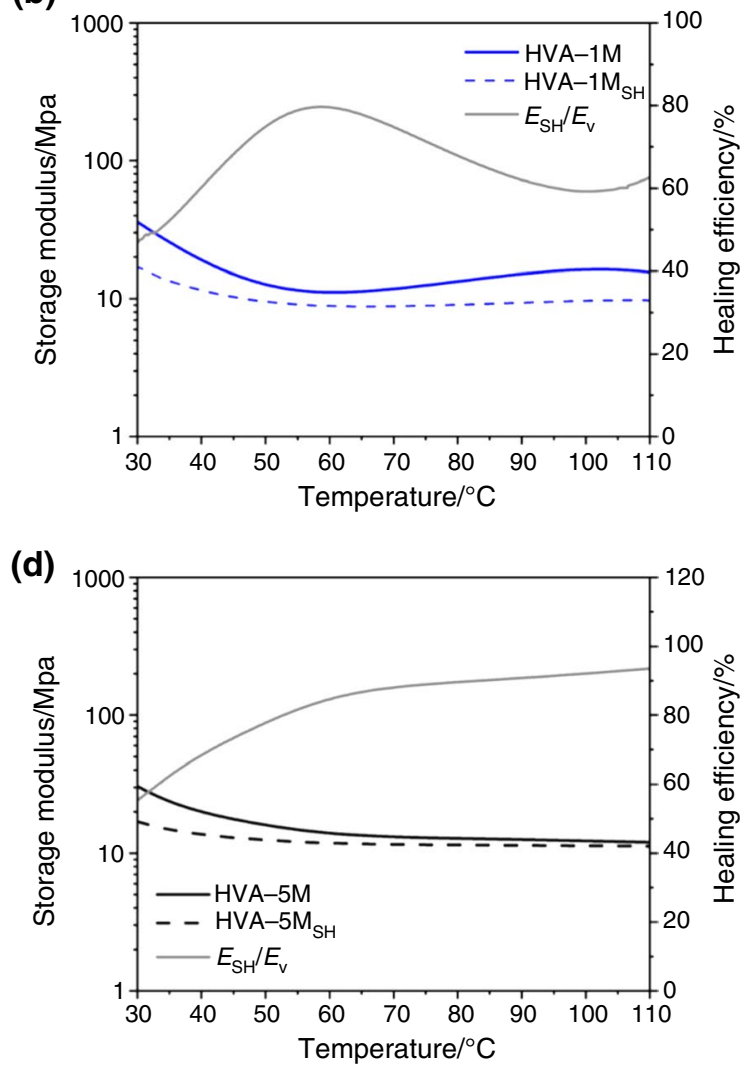

as function of temperature for the analyzed composites: a HVA, b HVA-1 M, c HVA-3 M, and d HVA-5 M 
that, the efficiency decreases with temperature up to $60 \%$ at the maximum value of temperature. Probably, this filler amount is not enough to contrast the negative effect of the temperature increase in destroying $\mathrm{H}$-bonding interactions. The addition of a bigger amount of Murexide, corresponding to 3 and 5 mass\% (see Fig. 5c, d) allows obtaining an almost total recovery of the storage modulus also at high values of temperatures. In fact, HVA-3 M and HVA-5 M samples manifest values of healing efficiency close to $100 \%$ in almost all the range of the analyzed temperatures. The obtained results clearly highlight that the presence of $\mathrm{M}$ filler boosts up the activation of self-healing interactions inside the HVA matrix. Its intrinsic ability to establish H-bonding interactions with the functional groups of the thermoplastic matrix and between the same molecules of Murexide is schematically represented in Fig. 6. The presence in the Murexide of multiple functional groups, acting as H-bonding acceptors $(\mathrm{C}=\mathrm{O})$ and donors $(\mathrm{O}-\mathrm{H}, \mathrm{N}-\mathrm{H})$, makes this molecule an excellent self-healing filler. Furthermore, it is evident that the Murexide exerts cumulative effects of the reversible interactions, which occur with the growth of the filler percentage up to $3 \%$ and confer to the polymeric system a value of self-healing efficiency higher than $80 \%$ at all the analyzed temperatures.

Very strong cumulative interactions, like those established in the sample containing 5 mass\% of M, slightly reduce the mobility of the chains and therefore the possibility to quickly restore the hydrogen-bond interactions. This behavior is also observed carrying out healing tests in dynamic conditions.

Figure 7 illustrates the results obtained evaluating the recovery of the storage modulus as a function of the temperature at different values of tensile deformation frequency. The measurements were taken for the samples with the lowest and the highest percentage of Murexide, HVA-1 M (see Fig. 7a, b) and HVA-5 M (see Fig. 7c, d), respectively. For both polymeric systems, the healing efficiency increases as the frequency increases. For both samples, the dependence of the healing efficiency on the frequency is lost at temperatures equal to/or higher than $90{ }^{\circ} \mathrm{C}$.

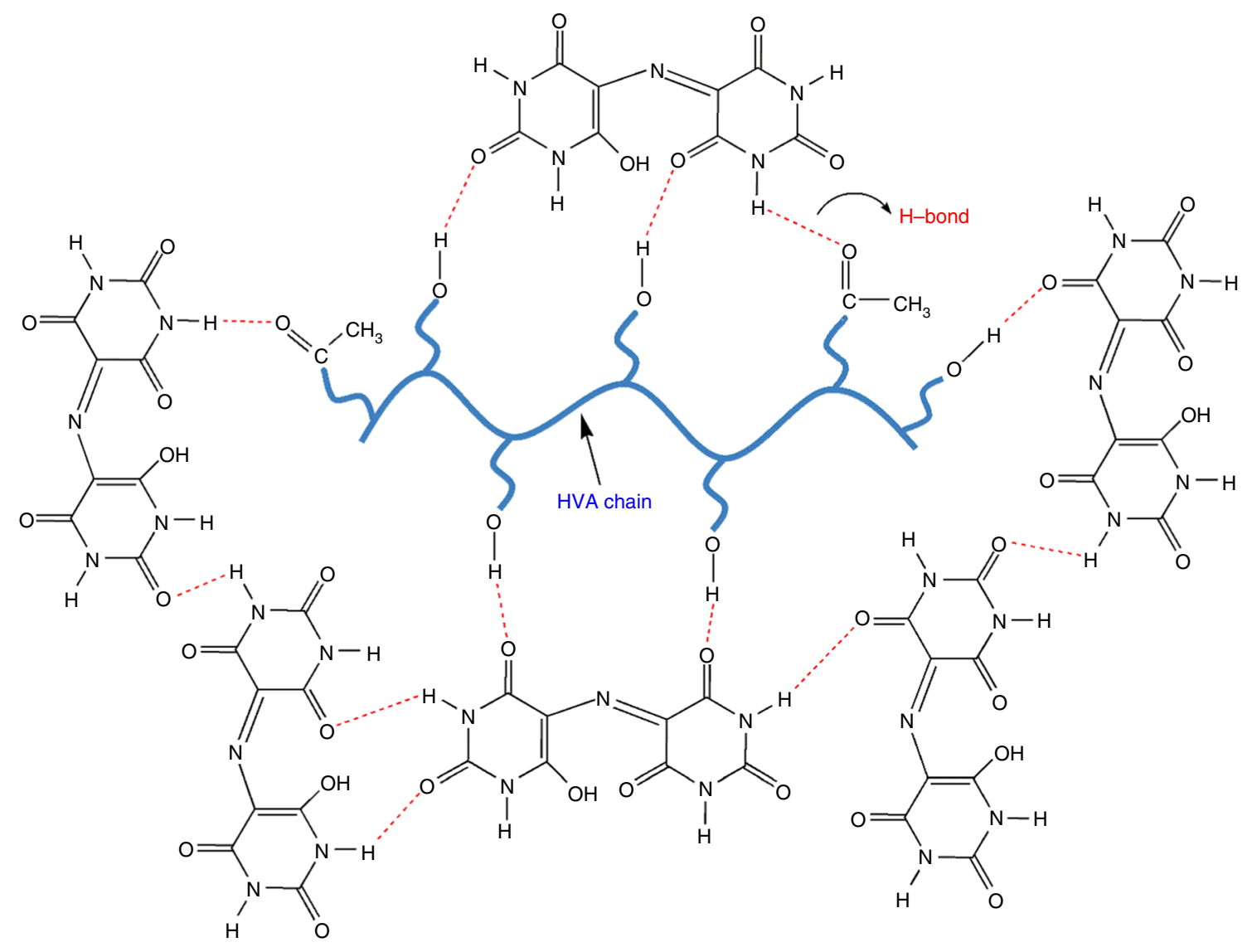

Fig. 6 Schematic representation of the H-bonding network due to the interactions established inside the HVA hosting matrix 

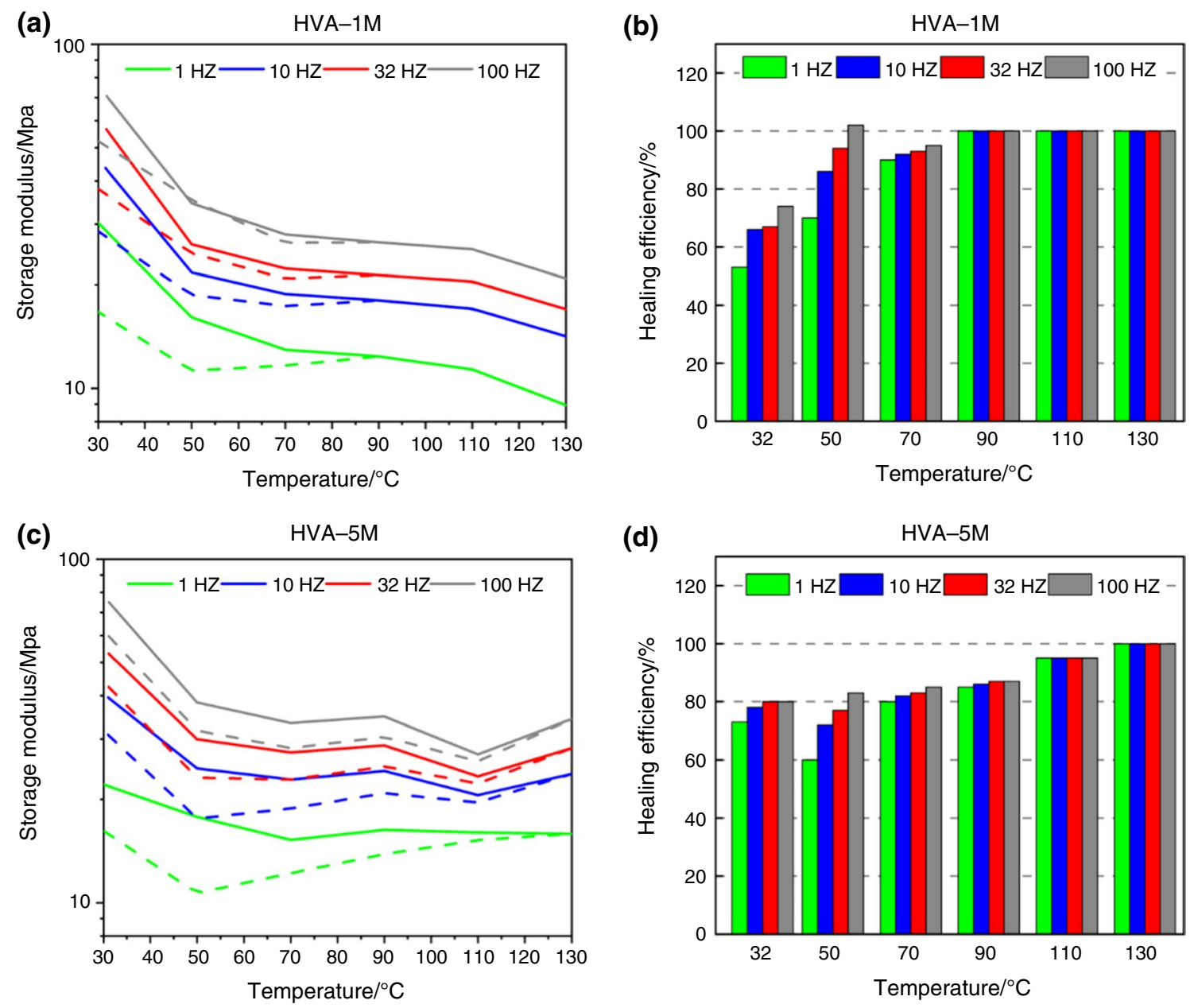

Fig. 7 a-c Storage Modulus as function of the temperature at different values of frequency, for the virgin sample (continuous curve) and for the healed sample (dashed curve), for the polymeric systems

This is probably due to the increased molecular mobility of the system produced by high values of temperature which acts in the same direction of the increase in frequency. The results of the dynamic tests also highlight that the best filler concentration to optimize the performance of the polymeric systems is 3 mass\%.

\section{Conclusions}

A thermoplastic biodegradable polymeric system has been formulated using Murexide salt and a vinyl alcohol copolymer (HVA). Murexide compound has been used as a selfhealing agent. Several amounts of Murexide have been employed to evaluate the effect of the filler concentration on the thermal and self-healing properties of the formulated systems. DSC investigation evidences that the increase of the amount of Murexide determines a slight decrease in the glass transition, crystallization, and melting temperatures. TGA

HVA-1 M and HVA-5 M, respectively; b-d Histograms showing the Healing Efficiency as function of the temperature at different values of frequency, for the composites HVA-1 and HVA-5 M, respectively

measurements highlight a very small reduction of thermal stability of the materials in the presence of a high concentration of Murexide. Despite this decrease, the polymer remains stable up to $270{ }^{\circ} \mathrm{C}$. Healing efficiency higher than $80 \%$, at a temperature beyond $60{ }^{\circ} \mathrm{C}$, is detected for the samples loaded with 3 and 5 mass $\%$ of Murexide. The highest healing efficiency values are detected for the sample loaded with a mass percentage of Murexide equal to 3\%. This result is also confirmed by detecting the healing efficiency in dynamic conditions, for which a healing efficiency equal to or close to $100 \%$ is detected at values of temperature equal to or higher than $90{ }^{\circ} \mathrm{C}$. The performed tests clearly evince the efficacy of the Murexide compound in boosting up the activation of self-healing interactions inside the HVA matrix.

Authors' contribution The authors have no conflicts of interest to declare that are relevant to the content of this article. 
Open Access This article is licensed under a Creative Commons Attribution 4.0 International License, which permits use, sharing, adaptation, distribution and reproduction in any medium or format, as long as you give appropriate credit to the original author(s) and the source, provide a link to the Creative Commons licence, and indicate if changes were made. The images or other third party material in this article are included in the article's Creative Commons licence, unless indicated otherwise in a credit line to the material. If material is not included in the article's Creative Commons licence and your intended use is not permitted by statutory regulation or exceeds the permitted use, you will need to obtain permission directly from the copyright holder. To view a copy of this licence, visit http://creativecommons.org/licenses/by/4.0/.

\section{References}

1. Blanco I. Lifetime prediction of polymers: To Bet, or Not to BetIs this the question? Mater. 2018;11:1383. https://doi.org/10.3390/ ma11081383.

2. Guadagno L, Raimondo M, Naddeo C, Longo P, Mariconda A. Self-healing materials for structural applications polymer. Eng Sci. 2014;54(4):777-84. https://doi.org/10.1002/pen.23621.

3. Longo P, Mariconda A, Calabrese E, Raimondo M, Naddeo C, Vertuccio L, Russo S, Iannuzzo G, Guadagno L. Development of a new stable ruthenium initiator suitably designed for selfrepairing applications in high reactive environments. J Ind Eng Chem. 2017;54:234-51. https://doi.org/10.1016/j.jiec.2017.05. 038 .

4. Calabrese E, Longo P, Naddeo C, Mariconda A, Vertuccio L, Raimondo M, Guadagno L. Design of self-healing catalysts for aircraft application. Int J Struct Integr. 2018;9(6):723-36. https:// doi.org/10.1108/IJSI-12-2017-0077.

5. Guadagno L, Vertuccio L, Naddeo C, Barra G, Raimondo M, Sorrentino A, Binder WH, Michael P, Rana S, Calabrese E. Functional structural nanocomposites with integrated self-healing ability. Mater Today: Proc. 2021;34:243-9. https://doi.org/10.1016/j. matpr.2020.03.051.

6. Wojtecki R, Meador M, Rowan S. Using the dynamic bond to access macroscopically responsive structurally dynamic polymers. Nat Mater. 2011;10:14-27. https://doi.org/10.1038/nmat2891.

7. Sijbesma RP, Beijer FH, Brunsveld L, Folmer BJB, Hirschberg JHKK, Lange RFM, Lowe JKL, Meijer EW. Reversible polymers formed from self-complementary monomers using quadruple hydrogen bonding. Sci. 1997;278(5343):1601-4. https://doi.org/ 10.1126/science.278.5343.1601.

8. Wool RP. Self-healing materials: a review. Soft Matter. 2008;4(3):400-18. https://doi.org/10.1039/B711716G.

9. Utrera-Barrios S, Verdejo R, Lopez-Manchado MA, Hernandez SM. Evolution of self-healing elastomers, from extrinsic to combined intrinsic mechanisms: a review. Mater Horiz. 2020;7:2882902. https://doi.org/10.1039/d0mh00535e.

10. Wemyssa AM, Bowenb C, Plessec C, Vancaeyzeelec C, Nguyenc GTM, Vidalc F, Wan C. Dynamic crosslinked rubbers for a green future: a material perspective. Mater Sci Eng R. 2020;141: 100561. https://doi.org/10.1016/j.mser.2020.100561.

11. Zhua M, Liua J, Gana L, Longa M. Research progress in bio-based self-healing materials. Eur Polym J. 2020;129: 109651. https:// doi.org/10.1016/j.eurpolymj.2020.109651.

12. Thakur VK, Kessler MR. Self-healing polymer nanocomposite materials: a review. Polymer. 2015;69:369-83. https://doi.org/10. 1016/j.polymer.2015.04.086.

13. Guadagno L, Sorrentino A, Delprat P, Vertuccio L. Design of multifunctional composites: new strategy to save energy and improve mechanical performance. Nanomater. 2020;10(11):2285. https:// doi.org/10.3390/nano10112285.

14. Guadagno L, Foglia F, Pantani R, Romero-Sanchez MD, Calderon $\mathrm{B}$, Vertuccio L. Low-voltage icing protection film for automotive and aeronautical industries. Nanomater. 2020;10(7):1343. https:// doi.org/10.3390/nano10071343.

15. Raimondo M, Naddeo C, Vertuccio L, Bonnaud L, Dubois P, Binder WH, Sorrentino A, Guadagno L. Multifunctionality of structural nanohybrids: the crucial role of carbon nanotube covalent and non-covalent functionalization in enabling high thermal, mechanical and self-healing performance. Nanotechnol. 2020;31(22): 225708. https://doi.org/10.1088/1361-6528/ab7678.

16. Guadagno L, Vertuccio L, Naddeo C, Calabrese E, Barra G, Raimondo M, Sorrentino A, Binder WH, Michael P, Rana S. Reversible self-healing carbonbased nanocomposites for structural applications. Polymers. 2019;11(5):903. https://doi.org/10.3390/polym 11050903.

17. Guadagno L, Mariconda A, Agovino A, Raimondo M, Longo P. Protection of graphene supported ROMP catalyst through polymeric globular shell in self-healing materials. Compos Part B-Eng. 2017;116:352-60. https://doi.org/10.1016/j.compositesb. 2016.10.075.

18. Guadagno L, Vertuccio L, Naddeo C, Calabrese E, Barra G, Raimondo M, Sorrentino A, Binder WH, Michael P, Rana S. Selfhealing epoxy nanocomposites via reversible hydrogen bonding. Compos Part B-Eng. 2019;157:1-13. https://doi.org/10.1016/j. compositesb.2018.08.082.

19. Kausar A. Self-healing polymer/carbon nanotube nanocomposite: A review. J Plast Film Sheeting. 2021;37(2):160-81.

20. Guadagno L, Naddeo C, Raimondo M, Barra G, Vertuccio L, Sorrentino A, Binder WH, Kadlec M. Development of self-healing multifunctional materials. Compos Part B-Eng. 2017;128:30-8. https://doi.org/10.1016/j.compositesb.2017.07.003.

21. Raimondo M, Calabrese E, Binder WH, Michael P, Rana S, Guadagno L. Tunneling atomic force microscopy analysis of supramolecular self-responsive nanocomposites. Polymers. 2021;13:1401. https://doi.org/10.3390/polym13091401.

22. Simon DA, Bischoff E, Buonocore GG, Cerruti P, Raucci MG, Xia H, Schrekker HS, Lavorgna M, Ambrosio L, Maulera RS. Graphene-based masterbatch obtained via modified polyvinyl alcohol liquid-shear exfoliation and its application in enhanced polymer composites. Mater Des. 2017;134:103-10. https://doi. org/10.1016/j.matdes.2017.08.032.

23. Yan N, Capezzuto F, Buonocore GG, Lavorgna M, Xia H, Ambrosio L. Gas-barrier hybrid coatings by the assembly of novel poly(vinyl alcohol) and reduced graphene oxide layers through cross-linking with zirconium adducts. ACS Appl Mater Interfaces. 2015;7:2267885. https://doi.org/10.1021/acsami.5b07529.

24. Donato ZK, Lavorgna M, Donato RK, Raucci MG, Buonocore GG, Ambrosio L, Schrekker HS, Mauler RS. High amorphous vinyl alcohol-silica bionanocomposites: tuning interface interactions with ionic liquids. ACS Sustain Chem Eng. 2017;1(5):1094105. https://doi.org/10.1021/acssuschemeng.6b02379.

25. Wang YL, Stanzione M, Xia H, Buonocore GG, Fortunati E, Kaciulis S, Lavorgna M. Effect of mercapto-silanes on the functional properties of highly amorphous vinyl alcohol composites with reduced graphene oxide and cellulose nanocrystals. Compos Sci Technol. 2020;200:108458. https://doi.org/10.1016/j.compscitech. 2020.108458.

26. Manzetti S, Gabriel JP. Methods for dispersing carbon nanotubes for nanotechnology applications: liquid nanocrystals, suspensions, polyelectrolytes, colloids and organization control. Int Nano Lett. 2019;9:31-49. https://doi.org/10.1007/s40089-018-0260-4.

27. Tunkol M, Durand J, Serp P. Carbon nanomaterial-ionic liquid hybrids. Carbon. 2012;12(50):4303. https://doi.org/10.1016/j. carbon.2012.05.017. 
28. Peng R, Wang Y, Tang W, Yang Y, Xie X. Progress in imidazolium ionic liquids assisted fabrication of carbon nanotube and graphene polymer composites. Polymers. 2013;5(2):847-72. https:// doi.org/10.3390/polym5020847.

29. Wang JY, Chu HB, Li Y. Why single-walled carbon nanotubes can Be dispersed in imidazolium-based ionic liquids. ACS Nano. 2008;12(2):2540. https://doi.org/10.1021/nn800510g.

30. Guadagno L, Vertuccio L, Naddeo C, Raimondo M, Barra G, De Nicola F, Volponi R, Lamberti P, Spinelli G, Tucci V. Electrical current map and bulk conductivity of carbon fiber-reinforced nanocomposites. Polymers. 2019;11(11):1865. https://doi.org/10. 3390/polym11111865.

31. Fabrício F, Silva AA, Soares BG. Epoxy-MWCNT composites prepared from master batch and powder dilution: effect of ionic liquid on dispersion and multifunctional properties. Polym, Eng Sci. 2018;58:1689-97. https://doi.org/10.1002/pen.24759.

32. Salzano de Luna M, Buonocore GG, Giuliani C, Messina E, Di Carlo G, Lavorgna M, Amrosio L, Ingo GM. Long-lasting efficacy of coatings for bronze artwork conservation: the key role of layered double hydroxide nanocarriers in protecting corrosion inhibitors from photodegradation. Angew Chem Int Ed Engl. 2018;25(57):7380-4. https://doi.org/10.1002/anie.201713234.

33. Guadagno L, Vertuccio L, Barra G, Naddeo C, Sorrentino A, Lavorgna M, Raimondo M, Calabrese E. Eco-friendly polymer nanocomposites designed for self-healing applications. Polymer. 2021;223: 123718. https://doi.org/10.1016/j.polymer.2021. 123718 .
34. Muppalaneni S, Omidian H. Polyvinyl alcohol in medicine and pharmacy: a perspective. Muppalaneni and Omidian. J Develop Drugs. 2013;2:3. https://doi.org/10.4172/2329-6631.1000112.

35. Marin E, Rojas J, Ciro Y. A review on polivinyl alcohol derivates: promising materials for pharmaceutical and biomedical applications. Afr J Pharm Pharmacol. 2014;8:674-84.

36. Musetti A, Paderni K, Fabbri P, Pulvirenti A, Al-Moghazy M, Fava P. Poly(vinyl alcohol)-based film potentially suitable for antimicrobial packaging applications. J Food Sci. 2014;79:E577-82. https://doi.org/10.1111/1750-3841.12375.

37. Guadagno L, Vertuccio L, Foglia F, Raimondo M, Barra G, Sorrentino A, Pantani R, Calabrese E. Flexible eco-friendly multilayer film heaters. Compos Part B. 2021;224:109208. https://doi. org/10.1016/j.compositesb.2021.109208.

38. Montero de Espinosa L, Meesorn W, Moatsou D, Weder C. Bioinspired polymer systems with stimuli-responsive mechanical properties. Chem Rev. 2017;20(117):12851-92. https://doi. org/10.1021/acs.chemrev.7b00168.

39. Peppas NA, Merrill EW. Differential scanning calorimetry of crystallized PVA hydrogels. J Appl Polym Sci. 1976;6(20):1457-65. https://doi.org/10.1002/app.1976.070200604.

Publisher's Note Springer Nature remains neutral with regard to jurisdictional claims in published maps and institutional affiliations. 